\title{
FONTE DA VIDA, DE \\ DARREN ARONOFSKY
}

\section{The Fountain, BY DARREN AronofSKY}

Mateus José Lannes Tolentino*

Fonte da Vida. Direção (roteiro) de Darren Aronofsky. Warner Bros. / Regency Enterprises / Protozoa Pictures. Estados Unidos: 2006. América do Norte: Warner Bros. Pictures, 22 nov 2006; Internacional: Regency Enterprises, 24 set 2006. [DVD]. (96 min), cor.

Caught in space and time like a bird in a cage Cruelly confined in a passing matters state You suddenly realize that the wrong is the right Daring the laws ready to put up a fight

Preso no espaço e no tempo como um pássaro numa gaiola Cruelmente confinado num estado transitório de matérias De repente você percebe que o errado é o certo

Desafia as leis e se prepara para um combate

Angra, Waiting Silence *

* Silêncio da Espera

<mateustolentino@hotmail.com.br> 
Um homem viaja através do tempo à procura de se tornar imortal para salvar o amor de sua vida: como um conquistador do século XVI, Tomás procura a lendária fonte da juventude; como um cientista na atualidade, Tommy luta desesperadamente para encontrar a cura do câncer que está matando sua mulher; e como um astronauta no século XXVI, Tom parece descobrir os mistérios da vida, amor e morte. Fonte da Vida apresenta três histórias diferentes, que se interligam de diversas formas e em momentos distintos, às vezes de maneira simultânea - cada uma das tramas apresentando um protagonista que tenta salvar, mas sem conseguir, alguém da morte iminente. Nas três situações, no entanto, a morte não significa o fim. Entende-se aqui que o filme é otimista ao mostrar a morte como o único caminho para se alcançar a plenitude (que não é obviamente a plenitude da vida), um ato de criação e renascimento, que serve como uma espécie de consolo para o enfrentamento do luto de um protagonista obcecado e inconformado com o fim da vida de uma personagem que não tem medo de partir. Essa dualidade, ao mesmo tempo que evoca o sentimento de valorização da existência humana, nos ajuda a entender que ela acabar é tão natural quanto necessário para que se mantenha o círculo da vida intacto. - E porque existe, nele, toda liberdade simbólica de expressão, toda harmonia clássica da forma, em suma, nada de imperfeito, essa figura, um lugar geométrico ao mesmo tempo sagrado e profano, exprime, não somente a existência humana em geral, mas, de modo altamente expressivo, e sob a forma de um enigma, a história biográfica de um indivíduo. Assim, em seu comentário sobre as Enéadas de Plotino, Marsílio Ficino observa que através dos hieróglifos os sacerdotes egípcios "tinham querido criar algo que correspondesse ao pensamento divino, já que a divindade detinha o saber de todas as coisas, não como uma ideia cambiante, mas como a forma simples e imutável das próprias coisas. [...] Como exemplo, ele cita o hieróglifo usado para representar o conceito do tempo - uma serpente alada, mordendo a extremidade de sua cauda. A multiplicidade e a mobilidade da concepção humana do tempo - como ele num rápido ciclo liga o princípio com o fim, como ele ensina a prudência, como ele traz e leva 
objetos - estão contidas, com toda essa série associativa, na imagem sólida e específica da serpente". ${ }^{1}$

Antes de mais nada, é importante definir o que é real e o que é ficcional em Fonte da Vida. Aquilo que se passa durante a Inquisição espanhola faz parte do livro que Izzi, no presente, está escrevendo. Já o núcleo temporal do que parece ser um monge e o núcleo temporal do médico são reais: o motivo para os dois terem uma aparência semelhante é justamente porque eles são a mesma pessoa, separados por um período de quinhentos anos. Assim, é importante frisar que Tom, o calvo de vestes rústicas que viaja numa árvore dentro de uma bolha, é o médico Tommy como um astronauta no futuro. Darren Aronofsky decidiu não tomar como referência os estereótipos do futuro estabelecidos hoje; assim, os astronautas daquela época não vestem um uniforme branco, nem viajam dentro de um foguete; assim, no século XXVI de Fonte da Vida, a nave espacial, como podemos ver, é de fato uma bolha. 0 que precisamos salientar agora é a aparência externa de Tommy na nave, sua atitude ascética diante da vida e da morte de sua amada. Pois nesse núcleo temporal é evidente a influência do monasticismo medieval no personagem de Tom, que "é ao mesmo tempo tirano e mártir. São as faces de Janus [...], os dois extremos [...]. Como tirano, ele encarna em sua plenitude a função soberana de proteger [...], por todos os meios a seu dispor. Como mártir ele leva às últimas consequências a virtude, e encarna plenamente a lei da criatura, e sua sujeição à morte, aceitando voluntariamente o suplício. Mas esses papéis são alternáveis. Em todo tirano existe um mártir, e em todo o mártir, um tirano. [...]. Nesse momento, ele [...] passa a despertar compaixão, como vítima por excelência do destino natural da criatura. [...]. É uma vítima da desproporção entre a dignidade desmedida de sua condição hierárquica e a miséria de sua condição humana. Inversamente, o mártir pode ser visto como um tirano, na medida em que se comporta como um estoico, e exerce sobre as paixões uma ditadura comparável à que o soberano exerce sobre os súditos. [...]. Como tirano, está exposto à conspiração, ao atentado, ao veneno. Como mártir, está condenado ao ascetismo e ao sofrimento. [...]. Ele hesita, porque está na fronteira de

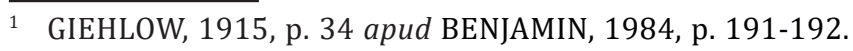

Revista Páginas de Filosofia, v. 10, n. 1, p. 209-216, jan.-jun. 2021 
dois mundos, porque sua condição é em si ambivalente. Ele é criatura, sujeito à natureza, e soberano, cuja tarefa é subjugar a natureza. 0 verdadeiro nome dessa hesitação é acedia, a sombria indolência da alma, traço mais geral da sintomatologia melancólica". ${ }^{2}$ Mas como suportaria viver centenas de anos sozinho naquele lugar? Talvez fosse impraticável, talvez mergulhasse na loucura. 0 ascetismo monástico é o princípio de razão suficiente do protagonista. De onde vêm então a parcimônia, o autocontrole, a sanidade? Eles vêm de uma história universal, ambientada numa época de conquista do Império Asteca pelos espanhóis, uma metáfora da vida real de Tommy Creo. Procurando na medicina uma forma de "curar" a morte, ele espera viver com sua mulher para sempre. ${ }^{3}$ Daí as passagens do livro se intercalarem com os momentos

2 Sérgio Paulo Rouanet, "Apresentação", 1984, p. 30.

3 Os alquimistas da Idade Média e Renascença baseavam suas ideias na tradição gnóstica, porém com uma diferença: enquanto os antigos gnósticos queriam transcender a matéria os alquimistas queriam redimi-la. "A matéria, que segundo a doutrina gnóstico-maniqueísta havia sido criada para promover a 'destartarização' do mundo, absorvendo em si o diabólico, para que com sua eliminação o mundo pudesse se apresentar purificado, lembra-se, através do diabo, de sua natureza 'tartárica', zomba de sua 'significação' alegórica e escarnece de todos aqueles que imaginam poder investigá-la, impunemente, em sua profundidade” (BENJAMIN, 1984, p. 250). Pois o processo alquímico clássico envolvia a dissolução dos elementos até o caos, para por meio desse estado de coisas separar massas indiferenciadas em essência espiritual e essência material, unindo essas oposições em uma espécie de "casamento alquímico", a pedra filosofal. "Porque mais uma vez a Antiguidade estava ameaçadoramente próxima do Cristianismo, naquela forma em que realizou um esforço final, relativamente bem-sucedido, de impor-se à nova doutrina: como gnosis. Com a Renascença, fortaleceram-se as correntes ocultistas, favorecidas pelos estudos neoplatônicos. 0 movimento rosa-cruz e a alquimia se desenvolveram paralelamente com a astrologia, o velho resíduo ocidental do paganismo do Oriente. A antiguidade europeia estava dividida, e suas obscuras reverberações medievais reviveram na imagem radiante do humanismo" (BENJAMIN, 1984, p. 244). Essa atividade alquímica reencenaria a atividade de Deus que separou o caos em elementos distintos, para mais tarde reunificar essas antinomias na Revelação. No entanto “ 'o cruel alquimista, a horrível morte' — essa profunda metáfora [...] não se baseia apenas no processo da decomposição. 0 conhecimento mágico, que inclui a alquimia, ameaça seus adeptos com a solidão e a morte espiritual. [...]. 0 modo de existência mais autêntico do Mal é o saber, e não a ação. Em consequência, a tentação física concebida em termos meramente sensoriais, como a luxúria, a gula e a preguiça, não constitui o fundamento único do Mal, e a rigor, não constitui um fundamento final e preciso. Esse reside, ao contrário, na miragem de uma espiri- 
que Tommy vive na realidade do filme. Tomás Creo procura a árvore da vida, Tommy Creo um meio de evitar o fim da vida. A história "verdadeira" do filme, uma vez que motiva e justifica o desenvolvimento do livro, e que, quanto ao mais, dá base de sustentação para o futuro que vemos em cena, é, portanto, aquela na qual acompanhamos a paixão de Tommy Creo, sua mulher prestes a morrer, ele incapaz de fazer algo a respeito. Pois na ânsia de encontrar uma forma de impedir a morte, ele perde os últimos momentos de convívio com sua esposa, o que piora e prolonga seu sofrimento. Izzi, porém, já havia aceitado seu destino; em contraposição ao marido, ela, em alguns momentos, afirma não ter medo de partir, porque vê na morte não o fim, mas o recomeço - libertação e renovação da alma. He said that if they dug his father's body up, it would be gone. They planted a seed over his grave. The seed became a tree. Moses said his father became a part of that tree. He grew into the wood, into the bloom. And when a sparrow ate the tree's fruit, his father flew with the birds. ${ }^{4}$

Tommy, entretanto, não compartilha dessa perspectiva. Obcecado em trazer sua mulher de volta à vida, encontra por meio da ciência uma "cura" para a morte, o que possibilita a ele viver séculos à frente de seu tempo. Porém, tarde demais. Nesse momento, Izzi já está morta. Desesperado, ele vai para casa e tatua o dedo anelar, como uma espécie de aliança eterna. Com isto temos a ligação do Creo do presente com o Creo do futuro, a demonstração matemática de que se trata da mesma pessoa (Tom Creo possui vários anéis que tatuou em si mesmo ao longo do tempo, o primeiro precisamente aquele tatuado

\footnotetext{
tualidade absoluta, isto é, sem Deus, associada à matéria como sua contrapartida, e que só no Mal pode ser experimentada concretamente. 0 estado de espírito que nele predomina é o luto, que gera a alegoria, e constitui seu conteúdo. Do luto, derivam três promessas satânicas originais, todas de natureza espiritual. [...]. O que seduz, é a ilusão da liberdade, na investigação do proibido; a ilusão da autonomia, no ato de segregar-se da comunidade dos crentes; e a ilusão do infinito, no abismo vazio do Mal" (BENJAMIN, 1984, p. 252-253). Esses aspectos simbolizariam o processo através do qual o adepto consegue refinar a sua alma.

4 "Disseram que se desenterrassem o corpo de seu pai eles veriam que ele se foi. Eles plantaram uma semente em seu túmulo. A semente virou uma árvore. Moisés disse que seu pai se tornara parte daquela árvore. Ele se fundiu à mata e floresceu. E quando um pardal comeu o fruto da árvore, seu pai voou com os pássaros".
}

Revista Páginas de Filosofia, v. 10, n. 1, p. 209-216, jan.-jun. 2021 
no dedo anelar logo após a morte de sua esposa; também a caneta que ambos usam para se tatuarem é a mesma, a sua versão do futuro totalmente desgastada pelo uso excessivo, o que reforça a tese de que se trata do mesmo objeto séculos depois). Como vemos, Izzi não pôde terminar o livro, deixando Tommy responsável por terminá-lo. É por isso que o tempo todo ele ouve a palavra - termine. Mas ele se recusa a fazê-lo, inconformado com o seu destino, e mesmo após muitos e muitos anos ele ainda não consegue aceitar sua perda individual, tão invariavelmente, tão profunda e absurdamente empenhado estava em trazê-la de volta à vida. Assim, em determinado momento Izzi conta uma história sobre a Xibalba, uma nebulosa que absorve estrelas em sua morte, e que segundo a mitologia maia tem a capacidade de reviver os mortos. Desafiando o destino natural dos seres viventes, Tommy espera ressuscitá-la ao fazer germinar a semente dada por ela, plantada em seu túmulo, cuja árvore armazenaria a energia para realizar seu intento maravilhoso, quando enfim atingisse Xibalba. (Note-se a relação entre a árvore e Izzi, devido a alguns detalhes, como quando Creo aproxima seus dedos e os fios do tronco se eriçam, da mesma forma que os pelos da nuca arrepiam ao toque dos seus lábios.) Portanto, a crença de que sua mulher existe através da árvore, e de que ela pode renascer ao chocar-se com a nebulosa, impulsiona Tommy a viver por centenas de anos sozinho naquela nave, viajando pelo espaço sideral profundo até o que ele acredita ser sua última esperança: Xibalba. Contudo a árvore morre um pouco antes de ele alcançar a estrela, assim como sua esposa morre um pouco antes de ele encontrar a cura para a morte, o que o faz cair novamente em desespero. Mas a cena de Tomás bebendo a seiva da árvore, transformando-se em flores, evidencia o fato de que Tommy finalmente encontrou a paz. E aqui termina o que ele imaginou para o livro. Pois enquanto estava na nave futurista, confrontado pela perda da única chance de ter sua esposa de volta à vida, Tommy compreendeu esse conceito particular de sua vida eterna, permitindo assim dissolver-se na nebulosa, cujos restos luminosos fizeram a árvore renascer com força renovada. "Todas as poesias da Antiguidade implicam umas nas outras até que, de massas e membros cada vez maiores, o todo é formado [...]. E verdadeiramente 
não constitui uma imagem vazia dizer: a poesia antiga é uma poesia única, indivisível e perfeita. Por que não pode ser novamente aquilo que uma vez já foi? De outro modo, se entende. E por que não de um outro modo mais belo e maior? "5

De resto, quando vai a uma exposição intitulada "Divine Words", Tommy ouve de Izzi a história do mito da criação segundo os maias, o qual dizia que o Primeiro Pai se sacrificou para fazer o mundo: a árvore da vida saiu de seu estômago; seu corpo tornou-se a raiz da árvore, formando assim a terra; sua alma tornou-se os galhos, para em seguida subir e formar o céu; e sua cabeça, pendurada acima das nuvens por seus filhos, transformou-se em Xibalba. De modo que a moral da história está em mostrar que a imortalidade não é concedida através da permanência em um único corpo: o ser humano viveria existências sucessivas através da natureza. Gramíneas e plantas germinam a partir do corpo de Tomás Creo, e como um simbolismo das novas formas de vida em profusão ele se torna, ainda que não tenha mais consciência, parte de um círculo de eterna existência. Somente "iluminado" consegue Tomás Creo atravessar o guardião do templo da Árvore da Vida, este reconhecendo nele a figura do Primeiro Pai, e entregando-se de bom grado para a morte. Quando enfim compreende isso, o Creo do futuro decide então morrer para viver para sempre com sua esposa.

Mas o livro existiu? Isabel sobreviveu à Inquisição espanhola, a despeito de que tenha sido por ela mesma instituída - e de que tenha eventualmente se voltado contra ela - , e abriu as portas do novo mundo para a era dos descobrimentos, como nos ensina a história natural do continente europeu. Ou é somente a deusa Sofia, ensinando o espírito cansado a elevação através de experiências que apenas a existência material pode proporcionar, ensinamento que por se dirigir ao corpo ama sua própria aflição? Tommy Creo, tolo sensato e ajudante incapaz de ajudar, lançou ao passado seu alter ego em busca de um objetivo e um pouco de consolo na vida. Rainha ou conquistador, pouco importa, desde que a alma seja aliviada da sua carga.

5 SCHLEGEL, 1906, p. 358 apud BENJAMIN, 1993, p. 96. 


\section{REFERÊNCIAS}

BENJAMIN, Walter. 0 conceito de crítica de arte no romantismo alemão. São Paulo: Editora da Universidade de São Paulo : Iluminuras, 1993. 146 p. (Biblioteca Pólen).

Origem do drama barroco alemão. Tradução, apresentação e notas de Sérgio Paulo Rouanet. São Paulo: Brasiliense, 1984. 276 p. (Elogio da filosofia).

GIEHLOW, Johann Carl Friedrich. Die Hieroglyphenkunde des Humanismus in der Allegorie der Renaissance, besonders der Ehrenpforte Kaisers Maximilian. Ein Versuch. Mit einem Nachwort von Arpad Weixlgärtner, 1915, p. 34 apud BENJAMIN, Walter. Origem do drama barroco alemão. Tradução, apresentação e notas de Sérgio Paulo Rouanet. São Paulo: Brasiliense, 1984. 276 p. (Elogio da filosofia).

SCHLEGEL, Friedrich. 1794-1802. Seine prosaischen Jugendschriften, 1906 apud BENJAMIN, Walter. 0 conceito de crítica de arte no romantismo alemão. São Paulo: Editora da Universidade de São Paulo : Iluminuras, 1993. 146 p. (Biblioteca Pólen). 